\title{
Creating an environmentally safe and reliable heat supply system through the introduction of energy-saving technologies in housing and common utilities services
}

\author{
Galina V. Astratova ${ }^{1,2, *}$, Tatyana K. Rutkauskas ${ }^{3}$, Konstantin V. Rutkauskas ${ }^{4}$, and Vladimir \\ V. Klimuk ${ }^{5}$ \\ ${ }^{1}$ Ural Federal University named after the first President of Russia B. N. Yeltsin, Department of \\ Integrated Marketing Communications and Branding, 620002 Ekaterinburg, Russia \\ ${ }^{2}$ Ural Juridical Institute of MIA of Russia, 620057 Yekaterinburg, Russia, \\ ${ }^{3}$ Ural Federal University named after the first President of Russia B. N. Yeltsin, Department of \\ Banking and Investment Management, Yekaterinburg, Russia \\ ${ }^{4}$ ERP Competence Center, Business Process Administration sector, 620142 Yekaterinburg, Russia \\ ${ }^{5}$ Baranovichi State University, 225411 Baranovichi, Belarus
}

\begin{abstract}
The rational use of natural resources and the creation of an environmentally safety is a priority goal for all mankind. The increasing pollution of the atmospheric air by the combustion products of various types of fuel actualizes the problem of improving the environmental safety and efficiency of heat supply systems (HSS).

Heating is the most energy intensive and wasteful sector of the national economy, because the turnover is comparable to $2.1 \%$ of GDP and an average of $50 \%$ in payment of citizens for housing and communal utility services (HCUS).

However, HSS today is in a critical state at all stages of production, distribution and consumption of heat, which is especially typical for HCUS enterprises in Russia. Accordingly, the population is not satisfied with the quality and price of HCUS services. The purpose of the study was to develop a mechanism for creating an environmentally safe and reliable HSS by introducing energy-saving technologies that can improve the quality and reduce the price of HCUS services.

The data analysis of the online survey of Russians in social networks in 2018-2019 is carried out. The average level of the population satisfaction with the quality of the provided services of HSS is determined.
\end{abstract}

\section{Introduction}

The rational use of natural resources and the creation of an environmentally safety is a priority goal for all mankind. Indeed, as noted in the Rio Declaration on Environment and Development, in order to effectively address the challenges of a deteriorating environment, States must cooperate to create an enabling and open international economic system that leads to economic growth and sustainable development in all countries [1].

\footnotetext{
* Corresponding author: galina_28@mail.ru
} 
In this regard, one of the key problems is the increasing pollution of the atmospheric air by the combustion products of various fuels, which actualizes the need to improve the environmental safety and efficiency of heat supply systems (HSS). In particular, the HSS analysis conducted by various researchers in the Russian Federation [2-8] shows that the currently widely used methods of protecting the natural environment are not always effective. This situation is primarily due to the fact that the unique district heating infrastructure built by the Soviet Union about 60 years ago has fallen into disrepair. The development was carried out by large design institutes, and by the 1980s the length of the country's heating networks reached 160 thousand kilometers. After the collapse of the Soviet Union, the unique model industry was expected and inevitably declined. According to the Russian Ministry of Energy, the average age of Russian stations today exceeds 30 years, and network wear is 40-60 percent [9]. A similar situation in terms of network wear was observed in Belarus [10]. However, in recent years, thanks to the state program "Energy Saving", the situation has significantly improved [11].

It is also important that heating is the most energy intensive and wasteful sector of the national economy, since turnover is comparable to $2.1 \%$ of GDP ( $\$ 1.5$ trillion RUB) and an average of $50 \%$ in payment of citizens for housing and communal utility services [12]. At the same time, in Belarus, the state program "Energy Saving" set the task to reduce the energy intensity of GDP in 2019 by $1.3 \%$, and in fact it was $2.5 \%$. Thus, the energy intensity of Belarus' GDP has improved in comparison with Canada and is close to that one's of Finland. Among the industrialized countries of the CIS, the energy intensity of Belarus ' GDP is 30\% lower compared to the same indicator in Russia [11].

In Russia also is realized the State energy efficiency program [13], according to which there is a wide range of activities the main activities of which is the implementation of a broad modernization of production and processing of energy resources, changes in the structure of resource use in heat and power systems and wide application of energy saving technologies.

At the same time, such an industry as housing and communal utility services (HCUS), both in Russia and in Belarus, is in the most difficult conditions, since the wear of heating networks is very significant. This leads to a critical state of heat supply at all stages of heat production, distribution and consumption ones for the HCUS' enterprises in Russia [12, 14, and 15]. Accordingly, the Russians are not satisfied with the quality and price of this brunch services [14, 15, 16, and 17].

The purpose of the study was to develop a mechanism for creating an environmentally safe and reliable HSS by introducing energy-saving technologies that can improve the quality and reduce the price of HCUS services

\section{Brief description of the state of heat supply of housing and communal utilities services in the Russian Federation}

The current state of the housing and communal utilities sector in the Russian Federation, in general, can be described as a crisis [12, 14, 18, 19, and 20].

Indeed, there is an increase in the level of depreciation of the housing stock in the industry [21, p. 95]. There is an overspending of energy resources in the HCUS [20].

The analysis of the economic activity of Russian HCUS's enterprises shows extremely low efficiency of business units in the industry, although it is quite stable and sufficient in the difficult conditions of reforms and institutional changes taking place in HCUS in recent years $[12,14,18,19$, and 20].

At the same time, thanks to the reform, in HCUS are being digitalized and attempts are being made to disclose data in the state information system of housing and communal utilities services [22, p. 245]. Consumer expectations of citizens are also actively studied, 
and first of all, such categories as: safety, environmental friendliness and comfort of the living environment of the population. It should be emphasized that the security of residence in accordance with paragraph 1 of Article 1 of the Housing Code of the Russian Federation is an inalienable right of Russians [23].

Therefore, market participants must constantly comply with this law.

The heat supply of the housing stock is closely connected with the safety of living. Heat supply has a dual mutually influencing essence of implementation, synthesizing, on the one hand, the interests of consumers, and on the other hand, the target orientation of heat energy producers. This type of service is also characterized by a specific life cycle, covering activities ranging from marketing research [17], design, technical implementation, inclusion of the consumer in the situation of receiving the service to analysis and further improvement of activities. Customer satisfaction is not limited only to the proper volume of service provision, but also includes a system of relationships aimed at forming and exceeding positive expectations [24, p.1].

An important category from the researchers' point of view is the quality of services, the essence of which is revealed in their uninterrupted provision and supply of the necessary parameters in the right volume in accordance with the requirements and needs of residents. It can be noted that in the works of domestic and foreign researches, on the basis of an integrated approach to assessing the housing quality, objective and subjective criteria for the life quality are synthesized [17, 24, 25, 26, 27]. For example, these quality characteristics include such as the design parameter's of a residential building, the assessment of the residence area, socio-economic aspects (the cost of housing and communal utilities services, maintenance of residential premises), comfort, etc. [16, p. 182$183]$.

At the same time, in the presented developments of domestic and foreign authors, there is no single approach to the formation of a mechanism for creating an environmentally safe and reliable heat supply system. The main distinguishing feature of the developments is that the HSS (centralized or decentralized) is considered, as a rule, in a closed space, limited geographically in certain conditions (a specific metropolis or other territorial unit).

However, inefficient heat supply led to a huge overspends of energy, material and financial resources, made heat generation uneconomical, and became an obstacle to the reform of HCUS. The analysis of statistical data shows the presence of constantly growing losses of heat energy up to $15 \%$ of the total amount of released heat energy, on average, 13 million tons Gcal per year [5, 14, and 20].

Large volumes of heat losses in heat networks are associated with their unsatisfactory physical condition. So, today the wear and tear of main and distribution networks reaches $70 \%$ of their total length. Technical condition of thermal networks of many settlements unsatisfactory thermal waterproofing, i.e. missing in the autumn and spring heat networks are flooded with water, which leads to increased losses and increased fuel consumption; lack of water treatment, boiler leads to significant corrosion and reduce the durability of thermal networks [14, p. 365].

Failures in the provision of heat regularly become a physical and moral suffering for many residents of the country in winter.

It is also important that the state of technological equipment and heat distribution systems directly affects the cost of HCUS. Thus, in 2018, compared to the previous period, prices for hot water supply increased by $6 \%$ and heating by $2.7 \%$ [28, p.163]. At the same time, it should be borne in mind that the maximum allowable share of citizens ' payment for all housing and communal utilities services in the total family income cannot exceed $22 \%$ [29], and its limit is set at $25 \%$ [30]. Therefore, direct increases in tariffs and energy prices for the population are strictly limited. 
The further increase in cash receipts from the population for financing directly depends on the level and rate of growth of the well-being of the country's citizens. It is with this factor that the reliability of operation and the sustainability of the development of heat supply are associated.

\section{Results of the population survey}

Based on the results of the analysis of Russian research and foreign experience, we set a goal to develop a mechanism for creating an environmentally safe and reliable HSS by introducing energy-saving technologies that can improve the quality and reduce the price of HCUS services

To achieve this goal, we have identified the following tasks:

* To determine the typology of residential premises in which citizens live;

* To study the main indicators that characterize the occupied total area of residential premises, the share of HCUS expenses in the average monthly income of the family, the average monthly income of the consumer, the possibility of assessing the objectivity of the items of expenses for the payment of services;

* To assess the life quality of the citizens' living environment, i.e., assess the level of environmental friendliness of the location of a residential building.

An online survey of the Russian Federation residents in social networks was conducted, collected and processed from 21.10.2018 to 1.11.2018; were received answers to 56 questions of 3581 respondents from 28.09.2019 to 28.12.2019 and were received answers to 66 questions of 2094 respondents. In order to identify the positive and negative aspects of the participants' activity in the HCUS market, the population aged 18 to 65 years and older was selected from the customer's position. The tool for conducting the survey was the service "Google-docs". The obtained data was processed using statistical methods of analysis. The representativeness of the sample was checked on the basis of the correlation analysis of the specific number ratio of respondents by age groups with the data of the Federal State Statistics Service of the Russian Federation [31] as of 01.01.2018 and 01.01.2019.

As a result of the study, we obtained the following data.

The largest number of respondents who took part in the survey falls on the age groups from 25 to 55 years. A larger number of respondents belong to the age group of 30-40 years, which is characterized by active entry into economic relations and participation in the reproduction of the population. This is confirmed by the results of our previous study [16].

The first task of the sociological study was to identify the typology of residential premises in which citizens live. Among the respondents, the largest numbers are the owners of residential premises. The owners of residential premises are $60 \%$ of respondents aged 25-29 and 30-40 years. The largest number of owners is represented in the Volga, Ural, and Siberian Federal Districts and in the Central part of Russia. In most cases, respondents live in apartments $-74.5 \%$ (1564 people) and a private house $-23.0 \%$ (482 people), in other places $-2.5 \%$, of which in a hostel $-2.0 \%$ (41 people) and barrack-type housing $-0.5 \%$ (12 people).

As a part of the second task solution, i.e. the amount of expenses for HCUS, it was found that in $22.2 \%$ of cases (466 respondents) these expenses account for $11-20 \%$ of the total monthly household income of the interviewees. The respondents were also asked to choose 3 items of expenses for HCUS that cause the greatest dissatisfaction among consumers. As a result, it was revealed that the most incomprehensible for customers are contributions for major repairs of apartment buildings, handling of solid municipal waste, maintenance of residential premises and heating costs due to the opacity of these types of 
services costs. The customers do not know what they pay for, what kind of expenses each of these items includes. It causes the huge dissatisfaction of the consumer.

Solving the third task of the study, the respondents were asked to assess the quality of the living environment, or the level of environmental friendliness of the location of a residential building. As a result, based on the responses received, the specific weight of the responses with a proper score for the row $(\mathrm{kj})$ was first determined, calculated by the ratio of the number of responses for each criterion $(\mathrm{kkj})$ to the total number of respondents who responded $(\mathrm{kr}$, in our case $\mathrm{kr}=2094$ people), multiplied by the corresponding score (bj) for the matrix column. Next, the result was divided by the maximum number of points $\left(b_{\max }\right.$, we have 7 points), and the level of environmental friendliness of the location of the residential building $\left(\mathrm{E}_{\mathrm{col}} \mathrm{i}\right)$ was determined for each of the criteria. For example, here is the $\mathrm{E}_{\mathrm{col}}$ calculation according to the air pollution criterion:

According to the formula (1) we have:

$$
E_{\text {ecol.i }}=\frac{\sum_{i=1}^{n} k_{j} \times b_{j}}{b_{\max }}
$$

$$
E_{\text {ecol } 1}=\frac{\frac{492}{2094} \times 1+\frac{318}{2094} \times 2+\frac{248}{2094} \cdot 3+\frac{248}{2094} \cdot 4+\frac{246}{2094} \cdot 5+\frac{219}{2094} \cdot 6+\frac{253}{2094} \cdot 7}{7}=0,47
$$

The values for $E_{\text {col }}$ i was obtained in the same way for each criterion for the level of environmental friendliness assessing.

The analysis of the obtained data showed that the lowest value is the indicator for the level of energy efficiency of the house $\left(E_{\text {col } i}=0.40\right)$, one of the reasons for this situation is an increase in the depreciation of the housing stock, and this is also due to the ecological culture of the population. According to $29 \%$ of respondents, the formation of the ecological culture of the population of the Russian Federation is at the level of three points out of seven possible.

The results obtained by us are consistent with the results of our previous study [16].

\section{Development of a mechanism for creating an environmentally safe and reliable heat supply system through the introduction of energy-saving technologies that improve the quality and reduce the price of housing and communal utilities services}

In accordance with the RF Law "On Environmental Protection" under the economic mechanism of environmental protection should understand the planning and financing of environmental activities, the legal regulation of payments for use of natural resources, emissions, discharges of pollutants into the environment, waste disposal and other harmful effects on it, provision of tax, credit and other benefits to environmental management entities in order to ensure better protection of the environment [31].

With regard to HCUS, the mechanism of environmental protection can be provided by creating an environmentally safe and reliable heat supply system. The analysis of the literature data shows that the following three areas of activity are the key areas for saving energy resources in HCUS: 1) improvement of regulatory, legal and economic mechanisms of energy saving; 2) improvement of technical solutions for energy saving; 3) transition to alternative energy sources [20].

In this article, we will adopt the second way, i.e., improving technical solutions for energy saving. In this regard, countries usually offer two options for normalizing heat supply: a central heat supply system (CHSS) and a decentralized heat supply system 
(DHSS). Each of these options is currently not sufficiently developed in relation to specific regional conditions.

The essence of these proposals is as follows. The first option involves mainly preserving the existing public CHSS by partially updating and reconstructing them. It is estimated that this will require about \$ 72 billion USD of capital investments until 2020. Such costs, with the expected increase in gas and coal prices by 2-3 times, will raise the price of heat by at least 3-4 times, which is economically unacceptable for socially significant consumers $[10,32]$.

The second option offers a massive rejection of CHSS and a widespread transition to the use of individual heat sources. However, such way is not very realistic for economic, technical, and organizational reasons [22].

Neither of these options is acceptable. It is necessary to combine them so rationally that, along with the zones of action of CHSS, the foci of DHSS can work effectively. It seems that such complementarities will increase the reliability and efficiency of heat supply and will help to bring it out of the crisis.

The forecast for the development of heat supply, which was developed in accordance with the possible economic growth options provided for in the energy strategy of Russia for the period up to 2030 [33], was based on the following principal areas of action:

* The intensive reduction of heat losses in the CHSS;

* The increase in the share of the population and the social sphere in the consumption of heat from the CHSS of general use;

* A significant increase in heat production in economic structures that are not associated with the CHSS of general use;

* The high growth rate of the number of progressive autonomous sources in DHSS;

* The intensive use of the energy saving potential in the reorganization of heat supply and heat consumption systems;

* The improving the reliability, efficiency and comfort of heat supply to the population $[22,33]$.

The main conclusion that follows from the state and forecast analysis of heat supply in the Russian Federation is that at present it is necessary to gradually implement the state concept and program for the development of HCUS until 2035 [34] of the country as a whole and its regions. Moreover, since August 2020, a number of indicators of the Housing and Communal Utilities Development Strategy until 2035 [34] have been adjusted in all regions in accordance with federal requirements for synchronizing strategic documents with state programs related, inter alia, to the changed macroeconomic situation caused by the Covid-19 pandemic. In addition, legislative acts were developed that should define and approve the main areas of action and the regulatory framework for the development of heat supply and heating at the federal and regional levels in Russia.

Currently, energy-saving, heat-recycling plants and other heat-protective measures have been developed for almost all types of production, but the level of energy efficiency of HCUS enterprises in Russia is significantly lower than that of foreign ones.

World practice of building residential buildings and the same practice in Russia shows that energy consumption in the residential sector alone can be reduced by at least $30 \%$ if the latest technologies for the production and operation of materials and equipment are introduced. A striking example of such technologies introduction is the Academic microdistrict of the city of Yekaterinburg, Sverdlovsk region.

Energy-saving technologies in general and in the Academic micro-district in particular should be implemented through a set of measures, including structural and engineering systems in the first place. For example, the use of sealed double-glazed windows (i.e., double-glazed windows in an aluminum cover). 
To prevent heat loss through the foundation, it is necessary to use thermal insulation, vapor protection and sufficient ventilation of the basement. Other energy-saving measures can be placed in a special group, such as: energy-saving lifestyle, training in energy-saving design and construction; use of artificial ventilation with heat recovery and reduction of uncontrolled air exchange; use of building materials with minimal energy consumption for their extraction and transportation; use of construction equipment without heavy energyintensive construction machines and equipment; computer mathematical modeling, optimization of all heat-protective characteristics and control over the operation of engineering systems, etc.

An energy-efficient building must have a reinforced thermal protection of enclosing structures (walls, floor, ceiling, windows, and doors); made of environmentally friendly materials. The microclimate in such a building is much better: at any time of the year, a person feels thermal comfort and fresh air. In an energy-efficient building, the cost of heating and hot water is reduced by three times.

Energy consumption for heating depends on the characteristics of the house. For example: size, thermal protection, quality of equipment, number of residents and their needs, etc. When organizing a heated space, it is necessary to remember that the energy loss is proportional to the total area of the enclosing structures, and the energy efficiency of the house is higher, the smaller the ratio of the area to the volume of the heated space. In the heated space of the house, it is not recommended to include structures that protrude in plan and vertical cross-section (turrets, loggias, bay windows, verandas, etc.). Simplification of forms and cutting off complex elements from the heated space can save up to $20-50 \%$ of energy [2-8].

The solution to the problem of energy-saving construction is impossible only through the use of traditional technologies and measures to increase the thermal protection properties of the external enclosing structures of the building. The introduction of new equipment for active energy saving is an urgent task, the solution of which is associated with the creation of ventilation systems, technologies for secondary energy resources, heat and cold supply systems, and the disposal of waste thermal ventilation emissions. Such systems use the heat of the ground and other non-traditional energy sources, two-pipe heating systems with controlled heat transfer, floor-ceiling heating systems, as well as systems for accounting and monitoring energy consumption and climate control.

Thus, the adoption and implementation of energy-saving design and engineering solutions are not only the key to creating an environmentally safe and reliable heat supply system in housing and communal utilities services, but also one of the mechanisms for environmental protection.

\section{CONCLUSION}

Rational use of natural resources and the creation of an environmentally safety is a priority goal in Russia, Belarus, CIS counties and for all mankind. The increasing pollution of atmospheric air by the combustion products of various types of fuel actualizes the problem of improving the environmental safety and efficiency of heat supply systems in general, and in the housing and common utilities sector in particular.

The formation of a mechanism for creating an environmentally safe and reliable heat supply system in the context of the development of sustainable relations between the state, the population and business can significantly increase the environmental friendliness, comfort and safety of both housing and common utilities services and citizens ' living in modern buildings. 


\section{References}

1. Rio Declaration on Environment and Development (1992)

2. A. A. Grishan, B. V. Gusev, Bulletin of the MSU, 4, 81-91 (2009)

3. A. A. Grishan, Energy-saving methodology of protection and restoration of naturaltechnical systems in examples of practical application (Dalnauka, Vladivostok, 2007)

4. R.S. Kuznetsov, Proceedings of the International Symposium "Reliability and Quality", 2, 16-21 (2016)

5. R.S. Kuznetsov, First Russia and Pacific Conference on Computer Technology and Applications, 291-293 (2010)

6. V.P. Chipulis, Proceedings of the International Symposium Reliability and Quality. 2, 273-277 (2013)

7. A.S. Nekrasov, Y.V. Sinyak, S.A. Voronina, V.V. Semikashev, Problems of Forecasting, 1(124), 30-43 (2011)

8. O.F. Tsuverkalova, Bulletin of the Altai Academy of Economics and Law, 11, 554-559 (2020)

9. Modernization of the Russian heat supply system will take from 7 to 12 years. [Electronic resource] Access Mode: https://finance.rambler.ru/other/43337117/?utm_content=finance_media\&utm_medium $=$ read_more\&utm_source $=$ copylink (accessed: 22.02 .2021$)$ (2021).

10. Official website of Belenergo. [Electronic resource], Access Mode: https://www.energo.by/ (accessed: 22.02.2021)

11. Energy intensity of Belarus ' GDP decreased by $2.5 \%$ in 2019\%. 24.02.2020. [Electronic resource], Access Mode: https://yandex.ru/turbo/sb.by/s/articles/energoemkost-vvp-belarusi-za-2019-godsnizilas-na-2-5.html (accessed: 22.02.2021) (2020)

12. Presentation by V.M. Kravchenko "Current state of the heat supply industry". (2016). [Electronic resource], Access Mode: https://ur.hse.ru/data/2016/03/28/1127797157/Кравченко\%20B.M._Текущее\%20состо яние\%20отрасли\%20теплоснабжения.pdf (accessed: 22.02.2021) (In Russian)

13. The State Program of the Russian Federation "Energy Development». (2019). [Electronic resource], Access Mode: https://minenergo.gov.ru/node/323(accessed: 22.02.2021)

14. Ya.P. Silin, G. V. Astratova, T.K. Rutkauskas, et al., Housing and communal services and the life quality in the XXI century: economic models, new technologies and management practices: a collective monograph (Publishing Center "Naukovedenie" Moscow, 2017)

15. T.K. Rutkauskas, Formation and development of market relations in housing and communal utilities services: theory, methodology and practice (Publishing House of the Russian State Vocational Pedagogical University, Yekaterinburg, 2005)

16. T.K. Rutkauskas, M.R. Chashchin, K.V. Rutkauskas, Housing strategies, 1(2), 181-208 (2020)

17. G.V. Astratova, E.V. Bazhenova, Marketing in housing and communal utilities services (Publishing Center "Naukovedenie", Moscow, 2016)

18. V.E. Serikova, Young scientist, 18 (204), 368-371 (2018)

19. O.N. Pugacheva, Education and science in the modern world. Innovations. 5(12), 120$128(2017)$ 
20. Y.O. Smirnova, A.D. Bibilashvili, Education and science in the modern world. Innovations, 1, 242-250 (2017)

21. A.A. Kushner, E.A. Azizova, Yu.V. Taraskina, Bulletin of the Astrakhan state technical University. Series: Economics, 2, 93-100 (2019).

22. N.V. Pakhomova, K.K. Richter, M.A. Vetrova, Bulletin of the Saint Petersburg state niversity. Economics, 33 (2), 244-268 (2017)

23. Housing Code of the Russian Federation 29.12.2004 N 188-FZ (ed. of 30.12.2020) (with amendments and additions, intro. effective from 02.01.2021)

24. S.A. Lysenin, E.V. Soldatova, Sistemnoye upravleniye, 1 (18), 23 (2013)

25. N. Lantsev, L. Reshetnyak, Quality of living. Public report July 2019 (2019)

26. N. Kosareva, T. Polidi, A. Puzanov, E. Trutnev, Ye. Igumenov, A study on the consistency between housing and urban planning policies (Higher School of Economics, Moscow, 2016)

27. G.V. Astratova, V.V. Klimuk, T.K. Rutkauskas, et al. Quality of life in the XXI century: current problems and prospects (Publishing house of the LLC " Positive Strategy", Yekaterinburg, 2014)

28. T.K. Rutkauskas, Actual issues of the development of modern society, economy and professional education. Materials of the XVII International Youth Scientific and Practical Conference, 1, 162-164 (2020)

29. On the assessment of the effectiveness of the activities of the executive authorities of the subjects of the Russian Federation and local self-government bodies of urban districts and municipal districts. Decree of the President of the Russian Federation No. 607 of 27.04.2008

30. On the assessment of the effectiveness of the activities of the executive authorities of the subjects of the Russian Federation and local self-government bodies of urban districts and municipal districts in the field of energy saving and energy efficiency improvement. Decree of the President of the Russian Federation No. 579 of 03.05.2010

31. Federal Law "On Environmental Protection" 10.01.2002 N 7-FZ (latest version)

32. Official website of the Federal State Statistics Service of the Russian Federation. [Electronic resource], Access Mode: https://rosstat.gov.ru/

33. Russia's energy strategy for the period up to 2030 (2009)

34. Strategy for the development of Housing and Communal Utilities Services in the Russian Federation Federations until 2035 (2014) 